\title{
Trends in Contemporary Endodontic Practice of Pakistan: A National Survey
}

\author{
Usman Anwer Bhatti ${ }^{1}$
}

Beenish Qureshi ${ }^{2}$

Saima Azam ${ }^{3}$

\author{
BDS, FCPS \\ BDS, FCPS \\ BDS, FCPS
}

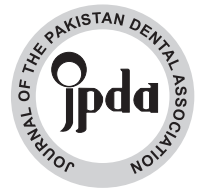

OBJECTIVE: The outcome of endodontic treatment is largely dependent on the selection of right armamentarium. The objective of this study was to determine the trends in contemporary endodontic practice of dental practitioners performing root canal treatment in Pakistan using a questionnaire based survey.

METHODOLOGY: This was a cross sectional study. To meet the objective of this study 518 questionnaires were distributed among the dental practitioners performing root canal treatment and associated with the academic dental institutions of Pakistan. Incompletely filled questionnaires and practitioners not willing to participate were excluded from the study. The questionnaire comprised of 22 questions addressing various aspects of endodontic treatment and the responses to these questions were analyzed using SPSS 22 to calculate frequencies and percentages. RESULTS: A total of 409 completed questionnaires were returned bringing the response rate to about $79 \%$. Most of the respondents performed more than 10 root canal treatment procedures in a month $(51.8 \%)$ comprising of a combination of anterior and posterior teeth including retreatment cases $(40.1 \%)$. The diagnosis of endodontic cases was primarily established by history and radiographs alone (39.1\%). Only $19.3 \%$ of the respondents reported the use of dental loupes for magnification. The use of preoperative angled radiographs for endodontic procedures was reported by $51.3 \%$ of the respondents while only $36.7 \%$ made use of film holding devices. About $46.9 \%$ reported only occasional use of rubber dam. Most preferred obturation technique and type of endodontic sealer was identified as cold lateral compaction (53.1\%) and Calcium hydroxide (32.5\%) respectively. While $68.5 \%$ respondents preferred multiple appointments with Calcium hydroxide as the most commonly used intracanal medicament (57.2\%). The use of anesthesia was restricted to access preparation (36.9\%) while $44.5 \%$ relied on a combination of antibiotics and NSAIDs for interappointment pain management. Radiographs (39.9\%) were the most preferred means for working length determination. Sodium Hypochlorite $(39.1 \%)$ was the most preferred irrigant with $63.6 \%$ making occasional use of EDTA. Activation of irrigants (58.4\%) was not routinely employed and use of $\mathrm{NiTi}(54.5 \%)$ rotary instruments was reported to be occasional.

CONCLUSION: This study observed deficiencies among dental practitioners in Pakistan providing endodontic treatment which should be addressed to improve the quality of endodontic care.

KEY WORDS: Questionnaire; Root canal treatment; Endodontists; Evidence based practice; Calcium Hydroxide; Sodium Hypochlorite

HOW TO CITE: Bhatti UA, Qureshi B, Azam S. trends in contemporary endodontic practice of pakistan: a national survey. J Pak Dent Assoc 2018;27(2):50-56.

DOI: https://doi.org/10.25301/JPDA.272.50

Received: 02 January 2018, Accepted: 22 February 2018

\section{INTRODUCTION}

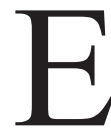

ndodontics is an evolving discipline with advancements in material and technology being scrutinized and carefully adopted under the umbrella

1. Assistant Professor, Department of Operative Dentistry, Islamabad Medical \& Dental College.

2. Associate Professor, Department of Operative Dentistry, Islamabad Medical \& Dental College.

3. Professor HOD, Department of Operative Dentistry, Islamabad Medical \& Dental College.

Corresponding author: "Dr. Usman Anwer Bhatti " < drusmananwer@gmail.com > of evidence based practice. As a consequence the dental practitioners offering root canal therapy are met with a myriad of choices. ${ }^{1}$ It becomes relevant to perform a national survey among dental practitioners of a given region to see how well they adopt evidence based guidelines in their endodontic practices as deviations from evidence based guidelines can have implications on the outcome of the delivered treatment.

Questionnaire surveys at a national level have been performed in different countries across the world like USA, 
UK, Switzerland, Denmark, Turkey, Jordan and India. ${ }^{1-7}$ Surprisingly even in a developed country like USA a staggering $68 \%$ of the endodontic treatments are being performed by the general practitioners. ${ }^{1}$ Similarly in Pakistan where there is a deficiency of dedicated endodontic training programs it would be expected that an overwhelming majority of the root canal treatments are being performed by general practitioners.

A plethora of endodontic armamentarium is available for use by the dental practitioners. However a sound endodontic practice is largely dependent on the selection and utilization of materials and techniques supported by research evidence. To the best of the author's knowledge a survey of this nature has not been performed in Pakistan.

National surveys on endodontic practice have been performed in different countries to assess the adaptation of newer technology and armamentarium. ${ }^{7}$ Most of these surveys included general practitioners of the country. Savani et al conducted a national survey in USA addressing the current endodontic trends among general practitioners and found $84 \%$ of the general practitioners had adopted newer technologies like digital radiography, magnification, electronic apex locators and NiTi rotary instruments. ${ }^{1}$

With the current approach of evidence based dentistry there is continuous research and improvement in guidelines for achieving better outcomes in root canal treatment. For the sake of our patient's health it would be important to see how well the dental practitioners of a given region adopt such practices.

The objective of this study was to determine the trends in contemporary endodontic practice of dental practitioners performing root canal treatment in Pakistan using a questionnaire based survey.

\section{METHODOLOGY}

This was a cross sectional survey of the general dental practitioners working in different academic institutes of Pakistan and involved in performing endodontic procedures either in academic or private capacity. A prior approval from the relevant institutional review board was acquired and a pre-piloted questionnaire survey adopted from Savani et al with slight modifications was used. ${ }^{1}$ The questionnaire comprised of 22 questions addressing different aspects of the endodontic treatment. In order to maintain anonymity the respondents were not asked to identify themselves. Also, the investigators were blinded as to the identification of the respondents but the details pertaining to years of practice and region of practice were recorded.

A sample size of $(n)=518$ was needed to meet the objective of this study as calculated using PS sample calculator with $90 \%$ confidence interval and anticipated population proportion $\mathrm{P}=0.5$. The pre-piloted questionnaires were distributed to the dental practitioners performing root canal treatment and associated with the academic dental institutions of Pakistan. Completed questionnaires were retrieved the same day or identified as a failure to respond. The data was tabulated and analyzed using the Statistical Program for the Social Sciences Software (version 22.0). Valid percentages were calculated based on the number of responses to each question.

\section{RESULTS}

A total of 518 questionnaires were sent and 409 completed questionnaires were returned bringing the response rate to about $79 \%$. Wherever multiple options could be selected it was highlighted in the question while multiple options selected for all other questions were identified as inappropriately filled. Table 1 shows the general characteristics of the respondents.

\section{Percentages}

\begin{tabular}{r|c|}
\hline Number of years in practice & \\
\hline $1-5$ years & 56.0 \\
\hline 6 -10 years & 24.7 \\
> 10 years & 19.3 \\
\hline Region of practice & \\
\hline Inappropriately filled & 1.5 \\
\hline Punjab & 54.3 \\
\hline Sindh & 19.3 \\
\hline KPK & 24.7 \\
\hline Balochistan & 0.2 \\
\hline Formal training in endodontics & \\
\hline Inappropriately filled & 0.5 \\
\hline Yes & 40.8 \\
\hline No & 58.7 \\
\cline { 2 - 2 } &
\end{tabular}

Table 1: General characteristics of respondents

Most of the respondents performed more than 10 root canal treatment procedures in a month $(51.8 \%)$ comprising of a combination of anterior and posterior teeth including retreatment cases $(40.1 \%)$. The diagnosis of endodontic cases was primarily established by history and radiographs alone $(39.1 \%)$ while only $13 \%$ relied additionally on cold testing (table 2). Only $1.5 \%$ of the respondents reported the use of microscope while $19.3 \%$ relied on dental loupes for magnification (table 3). About 51.3\% used preoperative angled radiographs and only $36.7 \%$ made use of film holding device. 
Response Percent

\begin{tabular}{c|c}
\hline Endodontic diagnostic tools & 6.6 \\
\hline History & 0.5 \\
\hline Cold Testing & 1.2 \\
\hline EPT & 18.6 \\
\hline Radiographs & 39.1 \\
\hline History and Radiograph & 14.2 \\
\hline History, Cold testing, EPT and & \\
Radiograph & 13.0 \\
History, Cold testing and & 5.6 \\
Radiograph & 0.5 \\
\hline History, EPT and Radiograph & 0.2 \\
\hline History and Cold testing & 0.2 \\
\hline EPT and Radiographs & 0.2 \\
\hline Cold testing and Radiographs & \\
\hline History, Cold Testing and EPT &
\end{tabular}

Table 2: Endodontic diagnostic tools

\begin{tabular}{|c|c|}
\hline Use of magnification tools & \\
\hline Inappropriately filled & 0.5 \\
\hline None & 78.7 \\
\hline Loupes & 19.3 \\
\hline Microscope & 1.5 \\
\hline \multicolumn{2}{|l|}{$\begin{array}{c}\text { Use of preoperative angled } \\
\text { radiographs }\end{array}$} \\
\hline Inappropriately filled & 2.4 \\
\hline Yes & 51.3 \\
\hline No & 46.2 \\
\hline \multicolumn{2}{|l|}{ Use of film holding devices } \\
\hline Inappropriately filled & 1.7 \\
\hline Yes & 36.7 \\
\hline No & 61.6 \\
\hline \multicolumn{2}{|l|}{$\begin{array}{c}\text { Method of working length } \\
\text { determination }\end{array}$} \\
\hline Inappropriately filled & 33.5 \\
\hline Tactile & 5.4 \\
\hline Radiographs & 39.9 \\
\hline Electronic apex locator & 4.6 \\
\hline Radiographs and apex locators & 16.1 \\
\hline None & 0.5 \\
\hline
\end{tabular}

Table 3: Magnification tools, angled radiographs, film holding devices, working length determination

Regarding the use of rubber dam $39.6 \%$ of the respondents did not utilize rubber dam for isolation and $46.9 \%$ indicated only occasional use. Table 4 shows the percentages of response for preferences regarding obturation technique, type of endodontic sealer, intracanal medicament, the number of appointments and the use of anesthesia. The percentage of response regarding interappointment pain management was $44.5 \%$ in favour of combined use of NSAIDs and antibiotics, with $37.9 \%$ respondents preferring exclusive use of NSAIDs alone.

For working length determination $39.9 \%$ of the respondents relied exclusively on radiographs while $16.1 \%$ relied on a combination of radiographs and apex locator. With respect to cleaning and shaping, table 5 highlights the preference for irrigants, use of EDTA, activation of irrigants and the use of NiTi rotary instruments for shaping root canal space.

Response Percent

\begin{tabular}{|c|c|}
\hline \multicolumn{2}{|l|}{ Preferred obturation technique } \\
\hline Inappropriately filled & 17.6 \\
\hline Cold lateral compaction & 53.1 \\
\hline Core carrier & 1.0 \\
\hline Paste filling & 1.0 \\
\hline Single cone & 20.0 \\
\hline Warm vertical compaction & 7.3 \\
\hline \multicolumn{2}{|l|}{ Preferred endodontic sealer } \\
\hline Inappropriately filled & 12.0 \\
\hline Calcium Hydroxide & 32.5 \\
\hline Endomethasone & 31.3 \\
\hline Epoxy Resin & 3.7 \\
\hline Zinc Oxide Eugenol & 20.5 \\
\hline \multicolumn{2}{|l|}{ Single vs multiple visits } \\
\hline Inappropriately filled & 2.0 \\
\hline Single & 4.6 \\
\hline Multiple & 68.5 \\
\hline No preference & 24.9 \\
\hline \multicolumn{2}{|l|}{ Use of anesthesia } \\
\hline Inappropriately filled & 3.2 \\
\hline Every appointment & 12.2 \\
\hline Access only & 36.9 \\
\hline Canal preparation only & 10.0 \\
\hline Access and obturation & 4.4 \\
\hline Access and preparation & 33.3 \\
\hline \multicolumn{2}{|l|}{$\begin{array}{c}\text { Preferred intracanal } \\
\text { medicament }\end{array}$} \\
\hline Inappropriately filled & 11.0 \\
\hline Calcium Hydroxide & 67.2 \\
\hline Ledermix & 5.6 \\
\hline Triantibiotic Paste & 3.7 \\
\hline No medicament used & 12.5 \\
\hline
\end{tabular}

Table 4: Preferred obturation technique, endodontic sealer, number of appointments, use of anesthesia and preferred intracanal medicament 


\begin{tabular}{|c|c|}
\hline & Response Percent \\
\hline \multicolumn{2}{|l|}{ Use of EDTA } \\
\hline Inappropriately filled & 1.2 \\
\hline Always & 26.2 \\
\hline Never & 9.0 \\
\hline Sometimes & 63.6 \\
\hline \multicolumn{2}{|l|}{ Preferred irrigant for cleaning } \\
\hline Inappropriately filled & 32.5 \\
\hline Saline & 24.4 \\
\hline Sodium Hypochlorite & 39.1 \\
\hline Biopure & 1.0 \\
\hline Chlorhexidine & 2.2 \\
\hline Hydrogen peroxide & 0.7 \\
\hline \multicolumn{2}{|l|}{ Irrigant activation } \\
\hline Inappropriately filled & 3.2 \\
\hline None & 58.4 \\
\hline Endoactivator & 5.4 \\
\hline Passive ultrasonic activation & 1.5 \\
\hline Manual activation & 31.5 \\
\hline \multicolumn{2}{|l|}{ Use of NiTi } \\
\hline Inappropriately filled & 1.7 \\
\hline Always & 25.4 \\
\hline Never & 18.3 \\
\hline Sometimes & 54.5 \\
\hline
\end{tabular}

Table 5: Use of EDTA, preferred irrigant, use of irrigant activation and $\mathrm{Ni}-\mathrm{Ti}$ rotary instrumentation

\section{DISCUSSION}

This study evaluated the preferences regarding materials and techniques employed in root canal therapy among dental practitioners employed in different academic institutes across Pakistan. A sample from academic institutes was selected because it was believed that an academic environment encourages practitioners to adopt more evidence based practice. The $79 \%$ response rate is encouraging for this study as other such surveys performed in different countries had a much smaller response rate, $24 \%$ for Savani et al, 35\% for Lee et al, $42 \%$ for Kohli et al, $43 \%$ for Kaptan et al. ${ }^{1,2,5,7}$ However, surveys performed by Raoof et al in Iran and Gupta et al in India have demonstrated a relatively higher response rate of $84.88 \%$ and $88 \%$ respectively. 8,9

Establishing a proper diagnosis is the first step in delivering appropriate treatment to a patient, various aids have been recommended to help guide the endodontist in this task. Although cold testing has been recognized by the literature to be more accurate in eliciting proper pulpal response and the subsequent diagnosis, only $13 \%$ of the practitioners relied on cold testing in this survey. The majority of the respondents $(39.1 \%)$ used history and radiographs alone to establish endodontic diagnosis. In contrast a survey of Iranian dental practitioners revealed about $38.5 \%$ of the respondents performed pulp sensibility tests prior to performing root canal therapy. ${ }^{8}$

Additionally, properly angulated radiographs are crucial in assessing case difficulty along with diagnosis and prognosis, yet only $51.3 \%$ of the respondents reported the use of preoperative angled radiographs and only $36.7 \%$ made use of some kind of film holding device. This is in contrast with the findings of Al Omari ${ }^{6}$ but comparable with Chandler et al. The use of film holding devices to ensure proper projection was limited to $36.7 \%$ which is in contrast with Chandler et al, suggesting that most practitioners in Pakistan are relying on bisecting angle technique which is more susceptible to projection errors. ${ }^{10}$

Despite the lack of evidence supporting the impact of magnification on endodontic treatment outcomes, the benefit of magnification in endodontics is recognized in terms of the predictability in identifying MB2 canals, however 78.3\% of the respondents did not employ any kind of magnification tool. ${ }^{11,12}$ Kaptan et al reported $17.1 \%$ dental practitioners in Turkey used loupes and only $3.2 \%$ had access to dental microscope. In contrast, studies in USA and India suggest the percentage of endodontists using microscope to be $91 \%$ and $56.5 \%$ respectively. ${ }^{2,7}$ This difference could be due to a difference in the sample population being investigated, general practitioners and endodontists, whereby the latter were more likely to inculcate magnification tools like microscope in their endodontic practices as observed in another study in USA by Savani et al where only $2 \%$ respondents made use of microscope. ${ }^{1}$

Despite the presence of guidelines by international endodontic associations like ESE (European Society of Endodontics) regarding the importance of placing rubber dam prior to endodontic procedure, ${ }^{13} 39.6 \%$ of the respondents reported never using rubber dam and only $13.2 \%$ made regular use of rubber dam. These values are still reasonable compared to those reported by Shrestha et al, Kaptan et al and Gupta et al but compared to the findings of Raoof et al, Kohli et al and Savani et al a much lower percentage of rubber dam usage was identified in our study. ${ }^{1,2,5,8,9,14}$

In terms of the number of appointment needed to complete the root canal treatment $68.5 \%$ of the respondents performed endodontic treatment in multiple visits while $29.4 \%$ had no preference. This is in contrast with the findings of Savani et al but in agreement with Omari et al. ${ }^{1,6}$ Regarding the use of intracanal medicament, $67.2 \%$ of the respondents in our study preferred Calcium Hydroxide which is consistent with the findings of Lee et al, Kohli et al, Gupta et, Unal et al but 
differ from those of Raoof et al, Shreshta et al who reported a much higher preference for it. ${ }^{1,2,7,8,9,14,15}$ Although this represents a relatively low usage of something that is supported by evidence, still the reported percentage is much higher than the study conducted by Omari et al, possibly because of the antiquated nature of the study. ${ }^{6}$

The nature of root canal treatment is such that most patients have preconceived apprehensions and anxiety, the role of anesthesia is very important to ensure patient comfort and cooperation during the treatment. Despite its significance however, most clinicians only delivered anesthesia in the appointment for access and canal preparation while a small number delivered it routinely in every appointment. These results are in agreement with Kohli et al and suggests a general anxiety among clinicians pertaining to delivering anesthesia for root canal treatment. ${ }^{2}$

For accurate determination of working length a combination of electronic apex locator (EAL) and radiographs is important but about $39.9 \%$ of the respondents relied exclusively on radiographs in our study while $16.1 \%$ relied on a combination of radiographs and apex locator. ${ }^{18}$ These findings are similar to those reported by Kaptan et $\mathrm{al}^{5}$ and others $6,7,9,14,15$ but differs from those reported by Savani et al,1 Kohli et al2 and Raoof et al8. Lee et al showed even in USA about half of the endodontists relied on EAL for length determination, considering which the results from Pakistani population are encouraging in terms of adoption of new technology. ${ }^{7}$ Alarmingly $5.5 \%$ of the respondents relied on tactile feedback which introduces grave inaccuracies in length determination. However, a large percentage of response was declared inappropriately filled $(33.5 \%)$ due to multiple option selection making it difficult to extract statistically relevant conclusions, better development of question to address this issue is required in future studies.

During cleaning and shaping, most respondents made occasional use of ethylene diamine tetra-acetic acid (EDTA) and majority (39.1\%) preferred Sodium Hypochlorite $(\mathrm{NaOCl})$ for irrigation, other studies investigating irrigation preferences in Pakistan reported similar findings. ${ }^{17}$ However, a lot of respondents (32.5\%) inappropriately filled this question by selecting multiple options, hence the results for this question cannot be considered a true representative of the population preferences. Majority of respondents in this study relied on occasional use of NiTi rotary files for shaping root canals despite evidence indicating their improved ability to shape but still about $80 \%$ were making use of NiTi at some frequency. ${ }^{18}$

Activation of the irrigant has been demonstrated by studies to improve distribution of irrigant in the root canal space especially resulting in improved cleaning. ${ }^{19}$ However only a small percent of the respondents utilized activation aids and even smaller relied on passive ultrasonic activation. This is in disagreement with Kohli et al who reported a greater use of ultrasonic activation possibly because the respondents were practicing endodontists in their study. ${ }^{2}$ Warm vertical compaction (WVC) has been shown to provide a more dense fill of the root canal irregularities but only $7.2 \%$ expressed their preference for WVC in our study and a much higher percentage relied on cold lateral compaction for sealing the root canal system..$^{20,21}$ This is in agreement with other studies possibly because lateral compaction remains the most widely taught technique in undergraduate programs and does not require procurement of expensive armamentarium. $1,2,6,8,9,14,15$

The seal is in part achieved by the type of sealer selected, and emerging evidence is in favour of using resin based sealers but still majority of respondents prefer using Calcium Hydroxide based sealers. This is in disagreement with a few studies possibly because of greater awareness among practicing endodontists compared to general practitioners. $2,5,6,8,8,9,14,15$

Although the results from in vitro studies regarding some endodontic armamentarium do not directly translate in to improved endodontic clinical outcome ${ }^{23}$ selection of right armamentarium is an important contributing factor to achieving clinically acceptable results. ${ }^{17,22,24,25}$ The use of basic tools like rubber dam represent an effort to minimize microbial contamination of the root canal space while use of NiTi ensures minimal risk of introducing aberrations in the root canal space. ${ }^{25}$ The limitations of this study include the presence of a percentage of inappropriately filled questions which could be improved by better designing and piloting of the questionnaires. Another limitation is the representation of only the practitioners associated with the academic institutes making the results of this study an over estimate of the general dental population practicing exclusively in private capacity.

\section{CONCLUSION}

Within the limitations of this study it can be concluded that there are deficiencies among dental practitioners providing endodontic treatment in Pakistan which should be addressed to improve the delivery of endodontic treatment and ensure better treatment outcomes.

\section{CONFLICT OF INTEREST/ FINANCIAL DISCLOSURE:}

The authors deny any plausible conflict of interest

The authors deny any financial interest in the subject matter or materials discussed in this manuscript. 


\section{REFERENCES}

1. Savani GM, Sabbah W, Sedgley CM, Whitten B. Current trends in endodontic treatment by general dental practitioners: report of a United States national survey. J Endod. 2014;40(5):618-24.

https://doi.org/10.1016/j.joen.2014.01.029

2. Kohli A, Singh S, Podar R, Dadu S, Kulkarni G. A comparative evaluation of endodontic practice trends in India: "The Mumbai study". Indian J Dent Res. 2014;25(6):729-36.

https://doi.org/10.4103/0970-9290.152179

3. Barbakow F. The status of root canal therapy in Switzerland in 1993. J Dent Assoc S Afr. 1996;51:819-22. 4. Slaus G, Bottenberg P. A survey of endodontic practice amongst Flemish dentists. Int Endod J. 2002;35(9):759-67. https://doi.org/10.1046/j.1365-2591.2002.00564.x

5. Kaptan R, Haznedaroglu F, Kayahan M, Basturk F. An investigation of current endodontic practice in Turkey. Sci World Journal [Internet]. 2012 [cited 2017 Dec 25];2012:16. Available from: https://www.hindawi.com/journals/ tswj/2012/565413/ DOI: 10.1100/2012/565413

https://doi.org/10.1100/2012/565413

6. Al-Omari WM. Survey of attitudes, materials and methods employed in endodontic treatment by general dental practitioners in North Jordan. BMC Oral Health [Internet]. 2004 Sep [cited 2017 Dec 25];4(1):1. Available from: http://bmcoralhealth.biomedcentral.com/articles/10.1186/1 472-6831-4-1 DOI: $10.1186 / 1472-6831-4-1$

https://doi.org/10.1186/1472-6831-4-1

7. Lee M, Winkler J, Hartwell G, Stewart J, Caine R. Current trends in endodontic practice: emergency treatments and technological armamentarium. J Endod. 2009;35(1):35-9 https://doi.org/10.1016/j.joen.2008.10.007

8. Raoof M, Zeini N, Haghani J, Sadr S, Mohammadalizadeh S. Preferred Materials and Methods Employed for EndodonticTreatment by Iranian General Practitioners. Iran Endod J. 2015; 10(2):112-16

9. Gupta R, Rai R. The Adoption of New Endodontic Technology by Indian Dental Practitioners: A Questionnaire Survey. J Clin Diagn Res [Internet]. 2013 [cited 201712 25]; 7(11):2610-14. Available from: https://www.ncbi.nlm.nih.gov/pmc/articles/PMC3879893/ https://doi.org/10.7860/JCDR/2013/5817.3628

10. Chandler NP, Koshy S. Radiographic practices of dentists undertaking endodontics in New Zealand. Dentomaxillofac Radiol. 2002 Sep;31(5):317-21

https://doi.org/10.1038/sj.dmfr.4600717

11. Del Fabbro M, Taschieri S. Endodontic therapy using magnification devices: a systematic review. J Dent. 2010;38(4):269-75 https://doi.org/10.1016/j.jdent.2010.01.008

12. Buhrley LJ, Barrows MJ, BeGole EA, Wenckus CS. Effect of magnification on locating the MB2 canal in maxillary molars. J Endod. 2002;28(4):324-7

https://doi.org/10.1097/00004770-200204000-00016

13. Loest C. Quality guidelines for endodontic treatment: consensus report of the European Society of Endodontology. Int Endod J. 2006;39(12):921-30

https://doi.org/10.1111/j.1365-2591.2006.01180.x

14. Shrestha D, Dahal M, Karki S. An endodontic practice profile amongst general dental practitioners in Kathmandu: a questionnaire survey. J Coll Med Sci Nepal. 2013;9(4):4050

15. Unal GC, Kaya BU, Tac AG, Kececi AD. Survey of attitudes, materials and methods preferred in root canal therapy by general dental practice in Turkey: Part 1. Eur J Dent. 2012;6(4):376

16. Haffner C, Folwaczny M, Galler K, Hickel R. Accuracy of electronic apex locators in comparison to actual length-an in vivo study. J Dent. 2005;33(8):619-25 https://doi.org/10.1016/j.jdent.2004.11.017

17. Hussain SM, Khan FR. A survey on endodontic irrigants used by dentists in Pakistan. Pak Oral Dent. 2014 Dec;34(4):730-34

18. Krug R, Krastl G, Jahreis M. Technical quality of a matching-taper single-cone filling technique following rotary instrumentation compared with lateral compaction after manual preparation: a retrospective study. Clin Oral Investig. 2017 Mar;21(2):643-652

https://doi.org/10.1007/s00784-016-1931-z

19. Caron G, Nham K, Bronnec F, Machtou P. Effectiveness of different final irrigant activation protocols on smear layer removal in curved canals. J Endod. 2010;36(8):1361-6 https://doi.org/10.1016/j.joen.2010.03.037

20. Keles A, Alcin H, Kamalak A, Versiani MA. Micro-CT evaluation of root filling quality in oval-shaped canals. Int Endod J. 2014;47(12):1177-84

https://doi.org/10.1111/iej.12269

21. Ho ES, Chang JW, Cheung GS. Quality of root canal fillings using three gutta-percha obturation techniques. Restor Dent Endod. $2016 \quad$ Feb;41(1):22 8.doi:10.5395/rde.2016.41.1.22. Epub 2016 Jan 4 https://doi.org/10.5395/rde.2016.41.1.22

22. Liang YH, Jiang LM, Jiang L, Chen XB, Liu YY, Tian FC, Bao XD, Gao XJ, Versluis M, Wu MK, van der Sluis L. Radiographic healing after a root canal treatment performed in single-rooted teeth with and without ultrasonic activation of the irrigant: a randomized controlled trial. J Endod. 2013 Oct; 39(10):1218-25

https://doi.org/10.1016/j.joen.2013.06.024

23. Peng L, Ye L, Tan H, Zhou X. Outcome of Root Canal 
Obturation by Warm Gutta-Percha versus Cold Lateral Condensation: A Meta-analysis. J Endod. Volume 33, 2007;33(2):106-109

24. Aqrabawi JA. Outcome of endodontic treatment of teeth filled using lateral condensation versus vertical compaction (Schilder's technique). J Contemp Dent Pract. 2006
Feb;7(1):17-24

25. Cheung GS, Liu CS. A retrospective study of endodontic treatment outcome between nickel-titanium rotary and stainless steel hand filing techniques. J Endod. 2009;35(7):938-43

https://doi.org/10.1016/j.joen.2009.04.016 